\title{
ISOLATED LUNG PERFUSION WITH MELPHALAN FOR THE TREATMENT OF METASTATIC PULMONARY SARCOMA
}

Sumihiko Nawata, MD

Nuno Abecasis, MD

Howard M. Ross, MD

Amir Abolhoda, MD

Huiming Cheng, MA

Komal S. Sachar, BS

Michael E. Burt, MD, PhD
Objective: Isolated lung perfusion allows the delivery of high-dose chemotherapy to the perfused lung and is an efficacious modality in the treatment of pulmonary metastases in the rat. Melphalan activity in this model was investigated. Methods: ToxICITy STUDY: Maximum tolerated dose of melphalan delivered by means of isolated lung perfusion was determined by survival after contralateral pneumonectomy. Pharmacokinetics study: Nineteen rats were treated with melphalan administered either by isolated lung perfusion ( $2 \mathrm{mg}$ ) or intravenously $(2 \mathrm{mg}$ or $1 \mathrm{mg}$ ). Lung, pulmonary effluent, and serum melphalan were analyzed by high-pressure liquid chromatography. EFFICACY STUDY: On day 0,41 rats received an intravenous injection of $5 \times 10^{6}$ methylcholanthrene induced sarcoma cells. On day 7 , rats either received intravenous melphalan ( $2 \mathrm{mg}[n=10] ; 1 \mathrm{mg}[n=8]$ ) or underwent left isolated lung perfusion with $2 \mathrm{mg}$ of melphalan $(n=12)$. Isolated lung perfusion with buffered hetastarch in sodium chloride (Hespan, $n=11$ ) was used as control. On day 14, pulmonary nodules were counted. Results: ToxicrTy: Maximum tolerated dose of melphalan delivered buy means of isolated lung perfusion was $2 \mathrm{mg}$. Pharmacokinetics: Left lung melphalan level was significantly higher in the isolated lung perfusion group (62.2 $\pm 34.3 \mu \mathrm{g} / \mathrm{gm}$ lung) than in the intravenous treatment groups $(6.9 \pm 1.9 \mu \mathrm{g} / \mathrm{gm}$ lung and $3.3 \pm 0.9 \mu \mathrm{g} / \mathrm{gm}$ lung, respectively) $(p=0.0002)$. EFFICACY: Significantly fewer left lung nodules were found in animals receiving melphalan by means of isolated lung perfusion $(7 \pm 10)$ than in the groups receiving intravenous melphalan $(60 \pm 21)$ or buffered hetastarch by isolated lung perfusion $(84 \pm 52)(p=0.01$ and $p=0.0001$, respectively). Conclusion: Isolated lung perfusion with melphalan is safe and effective in the treatment of pulmonary sarcoma metastases in the rat. (J Thorac Cardiovasc Surg 1996;112:1542-8)
$T^{1}$ he treatment of metastatic pulmonary sarcoma poses a significant clinical problem. Isolated pulmonary metastases will develop in approximately $20 \%$ of patients with soft tissue sarcoma of the extremities. Systemic chemotherapy holds little

From the Thoracic Oncology Laboratory/Department of Surgery, Memorial Sloan-Kettering Cancer Center, New York, N.Y.

Read at the Seventy-sixth Annual Meeting of The American Association for Thoracic Surgery, San Diego, Calif., April 28-May 1, 1996.

Received for publication May 6, 1996; revisions requested June 24, 1996; revisions received August 9, 1996; accepted for publication August 13, 1996.

Address for reprints: Michael Burt, MD, PhD, Memorial SloanKettering Cancer Center, Department of Surgery, 1275 York Ave., New York, NY 10021.

Copyright (c) 1996 by Mosby-Year Book, Inc.

$0022-5223 / 96 \$ 5.00+0 \quad \mathbf{1 2 / 6 / 7 7 3 2 6}$ promise for long-term survival. Although surgical resection remains the mainstay of treatment, 5-year survival approaches only $25 \% .^{2-5}$ Medical treatment failures are related to a high degree of sarcoma chemoresistance and the toxicity of therapy. Surgical treatment failures appear to be related to micrometastatic disease present at the time of surgical resection. ${ }^{5}$

We have developed a rodent model of isolated lung perfusion (ILP) to test a novel treatment strategy for pulmonary metastases. ${ }^{6}$ ILP allows the delivery of high-dose chemotherapy to the perfused lung while preventing systemic toxicity. ${ }^{7}$ Our laboratory has shown that metastatic sarcoma nodules can be eradicated with doxorubicin given by means of ILP. ${ }^{8}$ Doxorubicin is widely considered an effective agent against metastatic sarcoma. Many patients eligible to enter the ongoing phase I human 
ILP trial at the Memorial Sloan-Kettering Cancer Center have previously received the maximum tolerated systemic doses of doxorubicin. The availability of alternate agents for perfusion is, therefore, important, because emergence of chemoresistance to doxorubicin is a potential concern. Melphalan (L-PAM) has been shown to be an effective agent against soft tissue sarcoma when delivered via isolated limb perfusion. ${ }^{9-13}$ Evaluations of toxicity and efficacy of melphalan in an ILP model are of clinical interest in formulation of future treatment strategies against metastatic pulmonary sarcoma.

\section{Material and methods}

Animal care. Male Fischer F344 rats (Charles River Laboratories, Kingston, N.Y.) were used in all experiments. Animals were treated in accordance with the Animal Welfare Act and the "Guide for the Care and Use of Laboratory Animals" (NIH Publication No. 86-23, revised 1985). All experiments were approved by the Institutional Animal Care and Use Committee of Memorial Sloan-Kettering Cancer Center. Animals were allowed access to standard laboratory rat chow (Purina Rat Chow; Ralston Purina, St. Louis, Mo.) and water ad libitum. Housing was temperature controlled and provided a 12-hour light/dark cycle.

Preparation of tumor. The tumor used in efficacy experiments was a methylcholanthrene-induced sarcoma. This sarcoma has been serially passed subcutaneously in our laboratory and has been well characterized. ${ }^{14,15} \mathrm{Tu}-$ mor was harvested fresh from a tumor-bearing animal, and a single cell suspension was prepared. The suspension was created by mincing tumor into $1 \mathrm{~mm}^{3}$ chunks, then digesting the chunks in $0.8 \%$ Collagenase $\mathrm{D}$ solution (Boehringer Mannheim $\mathrm{GmbH}$, Mannheim, Germany) for 45 minutes at $37^{\circ} \mathrm{C}$. The suspension was washed twice in phosphate-buffered saline solution. Bilateral pulmonary metastases can be reproducibly established by injection of this cell suspension into an external jugular vein at a concentration of $5 \times 10^{6}$ cells $/ \mathrm{ml}$.

ILP. ILP via the left lung was performed by the method previously established in this laboratory. ${ }^{6}$ Animals were anesthetized with pentobarbital sodium $(50 \mathrm{mg} / \mathrm{kg})$ intraperitoneally and intubated endotracheally with a 16-gauge intravenous catheter under direct visualization through an otoscope. ${ }^{16}$ A Harvard Apparatus rodent volume ventilator (model 683, Harvard Apparatus Co., Inc., South Natick, Mass.) was used to ventilate the animals' lungs with room air at a tidal volume of $10 \mathrm{ml} / \mathrm{kg}$ and at a respiratory rate of $80 \mathrm{strokes} / \mathrm{min}$. Halothane was used to supplement anesthesia. The left side of the chest was shaved and prepared with a povidone-iodine $10 \%$ solution, and a left thoracotomy through the fourth intercostal space was performed. The left pulmonary artery and vein were visualized under an operating microscope (OpMi-1, $16 \times$; Carl Zeiss, Wotan, Germany). Microvascular clamps were placed proximally on the pulmonary artery and vein. An arteriotomy was performed and the artery was cannulated with a PE-10 catheter (Becton Dickinson \& Co.,
Parsippany, N.J.). Perfusate was delivered through this catheter. A pulmonary venotomy was created and effuent was collected by a suction catheter placed near the venotomy. At the completion of the perfusion, the arteriotomy was repaired with a single simple suture $(9-0$ Ethilon, Ethicon, Inc., Somerville, N.J.). The microvascular clamps were removed and the left lung was returned to its anatomic position. Pressure was applied with gauze placed over the lung to control the bleeding from the venotomy. Through a separate puncture wound, a 16gauge catheter connected to a $5 \mathrm{ml}$ syringe was introduced into the left side of the chest cavity to facilitate lung reexpansion. The thoracotomy incision was closed in three layers with 4-0 silk. When the animals were alert and breathing spontaneously, the chest and endotracheal tubes were removed.

In all experiments, animals were perfused for $20 \mathrm{~min}$ utes with melphalan (Alkeran, Burroughs Wellcome Co., Research Triangle Park, N.C.) or buffered $6 \%$ hetastarch in $0.9 \%$ sodium chloride solution (BHE) (Hespan, Du Pont Pharmaceuticals, Wilmington, Del.) at a rate of 0.5 $\mathrm{ml} / \mathrm{min}$. In the toxicity and efficacy studies, rats underwent 5 -minute washout with $\mathrm{BHE}$ at $0.5 \mathrm{ml} / \mathrm{min}$. In the pharmacokinetics study, rats underwent 10 -minute washout with BHE. All doses of melphalan represent total doses administered to each animal. Melphalan perfusate solutions were prepared by reconstituting lyophilized powder in the supplied diluent and performing appropriate dilutions with $\mathrm{BHE}$.

Experiment 1: Toxicity study. On day 0, 29 male F344 rats (235 to $275 \mathrm{gm}$ ) were randomized into six groups. Group I $(n=2)$ had ILP with $20 \mathrm{mg}$ of melphalan, group II $(n=6)$ had ILP with $5 \mathrm{mg}$ of melphalan, group III $(n=$ 6) had ILP with $2 \mathrm{mg}$ of melphalan, and group IV $(n=5)$ had ILP with BHE. Groups V $(n=5)$ and VI $(n=5)$ received $2 \mathrm{mg}$ or $1 \mathrm{mg}$ of melphalan via the external jugular vein. All animals underwent right (contralateral) pneumonectomy on day 21 to assess left lung function. On day 38 , arterial blood gases were measured in animals that survived contralateral pneumonectomy. Arterial blood samples were collected from the abdominal aorta of the anesthetized animals. Animals were subsequently put to death, and the lungs were retrieved and stained with hematoxylin and eosin for histologic examination. Daily weight was recorded after ILP or intravenous treatments.

Experiment 2: Pharmacokinetics. Nineteen male F344 rats $(250$ to $300 \mathrm{gm}$ ) were randomized into three groups. Group I $(n=8)$ had ILP with $2 \mathrm{mg}$ of melphalan. Group II $(n=5)$ and group III $(n=6)$ received $1 \mathrm{mg}$ or $2 \mathrm{mg}$ of melphalan via external jugular venous injection. The ILP group had a PE-90 (Becton Dickinson) catheter inserted into the pulmonary vein for collection of pulmonary effluent samples. The pulmonary effluent samples were collected at 2-minute intervals throughout the perfusion. At the completion of a 20 -minute melphalan perfusion and 5-minute BHE washout, blood samples were collected by cardiac puncture and both lungs were removed and frozen at $-70^{\circ} \mathrm{C}$ for later melphalan analysis. Animals receiving intravenous melphalan underwent laparotomies 20 minutes after injection, and blood samples were drawn from the abdominal aorta. Subsequently, the animals were 
Table I. Perioperative survivals

\begin{tabular}{lrc}
\hline & \multicolumn{2}{c}{ Perioperative survival (\%) } \\
\cline { 2 - 3 } & \multicolumn{1}{c}{$I L P$} & Pneumonectomy \\
\hline Melphalan 20 mg $(n=2)$ & 0 & - \\
Melphalan 5 mg $(n=6)$ & 100 & 0 \\
Melphalan 2 mg $(n=6)$ & 100 & 67 \\
BHE $(n=5)$ & 100 & 80 \\
\hline
\end{tabular}

Pneumonectomy indicates contralateral (right) pneumonectomy.

put to death and both lungs were removed for measurement of melphalan tissue levels.

Melphalan processing and measurement. High-pressure liquid chromatography (HPLC), based on the method described by Chang, ${ }^{17}$ Scott, ${ }^{18}$ and their associates, was used to measure melphalan concentration. Pulmonary effluent samples were centrifuged and supernatants were frozen at $-70^{\circ} \mathrm{C}$ for later processing. Tissue was homogenized in a siliconized glass homogenizer in acidic buffer (water and methanol [1:1] with $1 \%$ acetic acid) in a 1:4 proportion and then centrifuged. Dansylproline (Sigma Chemical Company, St. Louis, Mo.) was used as an internal standard and was dissolved in methanol $(0.25 \mu \mathrm{g} / \mathrm{ml})$. Then $2 \mathrm{ml}$ or $200 \mu \mathrm{l}$ of internal standard solution was added to $1 \mathrm{ml}$ of effluent supernatant or 100 $\mu$ l of tissue homogenate supernatant. Samples were mixed vigorously on a vortex mixer, cooled at $-60^{\circ} \mathrm{C}$ (acetone and Dry Ice) for 3 minutes, and centrifuged. The supernatant was analyzed by HPLC. The HPLC system consisted of a Perkin-Elmer pump series 410 LCI, Autosampler ISS 200, and integrator LCI 100 (Perkin-Elmer Corp., Plainview, N.J.). Melphalan was detected at $254 \mathrm{~nm}$ wavelength on spectrophotometric detector (model LC 75, Perkin-Elmer Corp., Norwalk, Conn.). A $50 \mu \mathrm{l}$ sample was injected into a Symmetry $\mathrm{C}^{18}$ reversed-phase $3.9 \times$ $150 \mathrm{~mm}$ HPLC column (Waters Corp., Milford, Mass.). The mobile phase was composed of water and methanol (1:1) with $1 \%$ acetic acid, at a flow rate of $1.5 \mathrm{ml} / \mathrm{min}$. All chemicals were high purity (HPLC grade).

Experiment 3: Efficacy study. Forty-one male F344 rats (225 to $275 \mathrm{gm}$ ) were randomized into four groups. On day 0 , all groups underwent an intravenous injection of $5 \times 10^{6}$ methylcholanthrene-induced sarcoma cells via the right external jugular vein. On day 7 , group I $(n=10)$ received $2 \mathrm{mg}$ of melphalan intravenously; group II $(n=$ 8) received $1 \mathrm{mg}$ of melphalan intravenously; group III ( $n=12$ ) underwent ILP with $2 \mathrm{mg}$ of melphalan; group IV $(n=11)$ underwent ILP with BHE. On day 14 , rats were sacrificed and their lungs were stained with India ink for identification of pulmonary sarcoma nodules. ${ }^{19}$

Statistical analysis. All data are presented as mean \pm standard deviation. Pharmacokinetic data were analyzed by analysis of variance (ANOVA) test. Paired comparisons of the efficacy data between the melphalan ILP and the intravenous or BHE treatment groups were performed by means of the independent Student's $t$ test. Significance was defined as $p<0.05$.

\section{Results}

Toxicity study. Rats undergoing isolated lung perfusion with $20 \mathrm{mg}$ of melphalan died immediately after perfusion. Animals perfused with $5 \mathrm{mg}$ of melphalan survived ILP but died within a few hours after contralateral pneumonectomy. All animals perfused with $2 \mathrm{mg}$ of melphalan or BHE survived ILP. Rats perfused with $2 \mathrm{mg}$ of melphalan or BHE lost weight after ILP for 3 to 4 days and then recovered. Rats perfused with $2 \mathrm{mg}$ of melphalan or BHE survived contralateral pneumonectomy at rates of $67 \%$ and $80 \%$, respectively (Table I). Rats that received $2 \mathrm{mg}$ of melphalan intravenously died within 5 days of injection. All rats receiving $1 \mathrm{mg}$ of melphalan intravenously survived.

The histologic examination of the perfused lungs in groups II through IV showed evidence of alveolar cell hyperplasia. The lungs harvested from animals in group I showed severe congestion and mild-tomoderate hemorrhage. Mild-to-moderate congestion and hemorrhage were seen in group II. Varying degrees of pleural fibrosis and pleuritis were found in all groups except group I (Fig. 1). Arterial blood gas analysis on day 38 revealed a significant difference in oxygen tension, carbon dioxide tension, and $\mathrm{pH}$ between the melphalan ILP group and BHE ILP group (Table II).

Pharmacokinetics study. Lung melphalan levels were measured for all groups. Left lung melphalan levels were significantly higher in the melphalan ILP group (62.2 $\pm 34.3 \mu \mathrm{g} / \mathrm{gm}$ lung) than in the intravenous treatment groups $(6.9 \pm 1.9 \mu \mathrm{g} / \mathrm{gm}$ lung in 2 $\mathrm{mg}$, given intravenously, $3.3 \pm 0.9 \mu \mathrm{g} / \mathrm{g}$ lung in $1 \mathrm{mg}$, given intravenously) (Table III). Melphalan levels in the pulmonary venous effluent in the ILP group became elevated after 2 minutes and were almost constant throughout the 20 minutes of perfusion. At the end of the washout, melphalan levels of the venous effluents approached zero (Fig. 2). Serum melphalan levels in all groups were analyzed. No melphalan was detected in the serum of animals that received melphalan ILP. Serum melphalan levels in the groups receiving $1 \mathrm{mg}$ and $2 \mathrm{mg}$ intravenously were $1.5 \pm 0.5 \mu \mathrm{g} / \mathrm{ml}$ and $2.5 \pm 0.7 \mu \mathrm{g} / \mathrm{ml}$, respectively (see Table III).

Efficacy study. The number of left lung lesions was significantly less in animals receiving melphalan via ILP as compared with those receiving $1 \mathrm{mg}$ of melphalan intravenously or BHE ILP ( $7 \pm 10$ vs $60 \pm 21$ and $84 \pm 52$ ) (Table IV). Melphalan ILP resulted in a significant reduction of tumor nodules in the treated left lung as compared with the right 

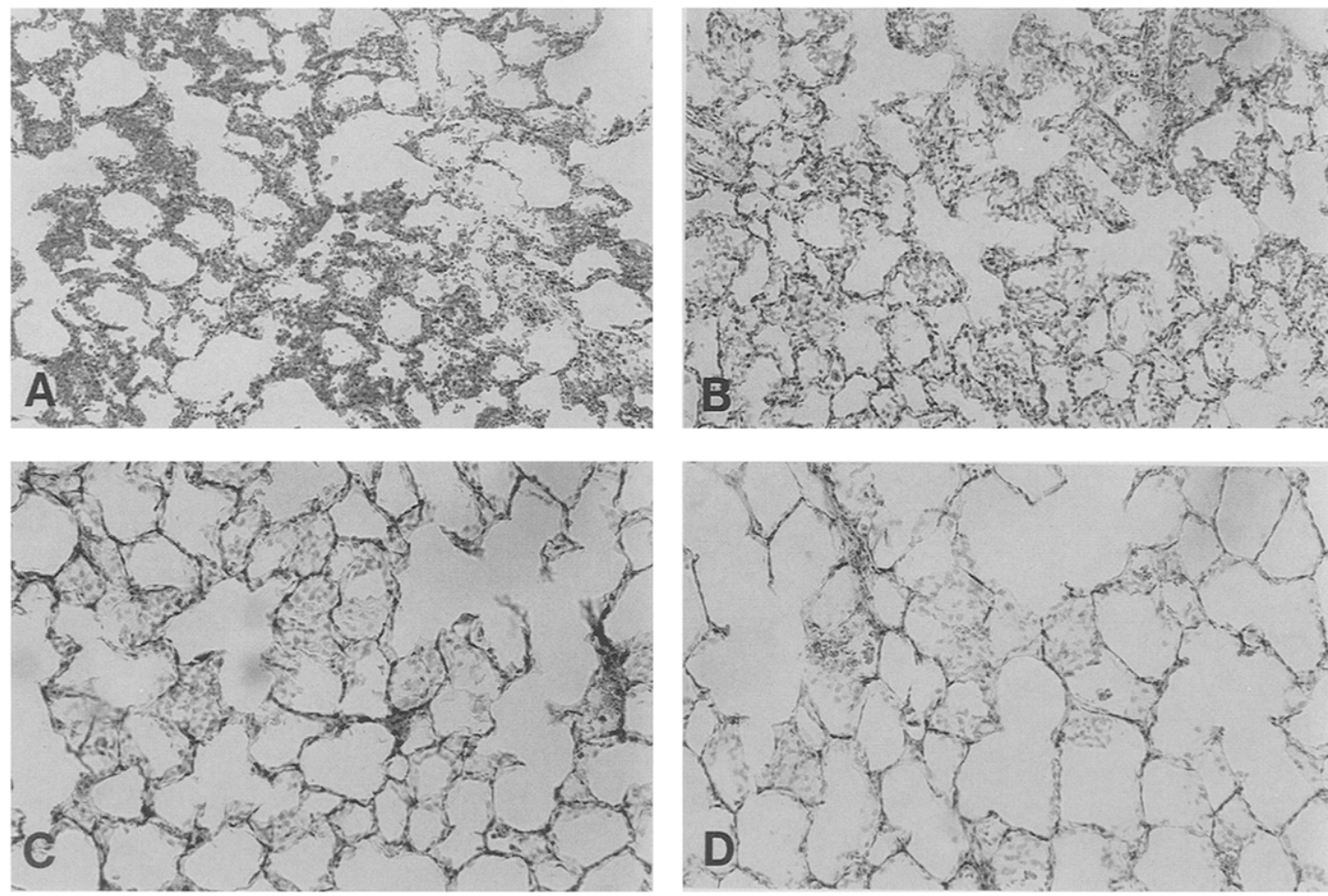

Fig. 1. Histologic findings of the perfused lungs. A, Group I: ILP with $20 \mathrm{mg}$ of melphalan. B, Group II: ILP with $5 \mathrm{mg}$ of melphalan. C, Group III: ILP with $2 \mathrm{mg}$ of melphalan. D, Group IV: ILP with BHE. (Original magnifications $\times 100$.)

Table II. Arterial blood gas analysis on day 38

\begin{tabular}{|c|c|c|c|}
\hline & $\mathrm{PO}_{2}(\mathrm{~mm} \mathrm{Hg})^{*}$ & $\mathrm{PCO}_{2}(\mathrm{~mm} \mathrm{Hg})+$ & $p H+$ \\
\hline $\begin{array}{l}\text { Melphalan } 2 \text { mg ILP } \\
\quad(n=4)\end{array}$ & $61.5 \pm 11.0$ & $52.5 \pm 7.3$ & $7.39 \pm 0.05$ \\
\hline $\begin{array}{r}\text { BHE ILP } \\
(n=4)\end{array}$ & $90.5 \pm 16.1$ & $35.5 \pm 9.5$ & $7.49 \pm 0.06$ \\
\hline $\begin{array}{l}* p=0.02 \\
\ddagger p=0.03 \\
\ddagger p=0.04\end{array}$ & & & \\
\hline
\end{tabular}

lung $(7 \pm 10$ vs $185 \pm 70)(p=0.000001)$. All rats that received melphalan $2 \mathrm{mg}$ intravenously died within 5 days of injection.

\section{Discussion}

Isolated pulmonary metastases will develop in approximately $20 \%$ of patients with soft tissue sarcoma of the extremities. ${ }^{1}$ Surgical resection of pulmonary metastases from soft tissue sarcoma is a widely accepted form of potentially curative therapy. However, the majority of these patients eventually die as a result of recurrence within the lung. ${ }^{1}$ Failure
Table III. Lung and serum melphalan levels

\begin{tabular}{lccc}
\hline & $\begin{array}{c}\text { Left lung } \\
(\mu g / g)\end{array}$ & $\begin{array}{c}\text { Right lung } \\
(\mu g / g)\end{array}$ & $\begin{array}{c}\text { Serum } \\
(\mu g / m l)\end{array}$ \\
\hline $\begin{array}{c}\text { Melphalan } 2 \text { mg ILP } \\
(n=8)\end{array}$ & $62.2 \pm 34.3$ & 0 & 0 \\
$\begin{array}{c}\text { Melphalan } 1 \mathrm{mg} \text { i.v. } \\
(n=5)\end{array}$ & $3.3 \pm 0.9$ & $2.4 \pm 1.4$ & $1.5 \pm 0.5$ \\
$\begin{array}{c}\text { Melphalan } 2 \mathrm{mg} \text { i.v. } \\
(n=6)\end{array}$ & $6.9 \pm 1.9$ & $7.8 \pm 5.3$ & $2.5 \pm 0.7$ \\
\hline
\end{tabular}

i.v., Intravenous.

of surgical treatment appears to be related to micrometastatic disease present at the time of surgical resection. ${ }^{15}$

In an attempt to address the clinical problem of micrometastatic pulmonary sarcoma, our laboratory developed a model of ILP in the rat. ${ }^{6}$ ILP with doxorubicin was shown to be effective in eradicating metastatic sarcoma in the rats, and a phase I trial of doxorubicin ILP in man is underway.

The present study evaluated melphalan as an antisarcoma agent delivered via ILP. Clinical studies 


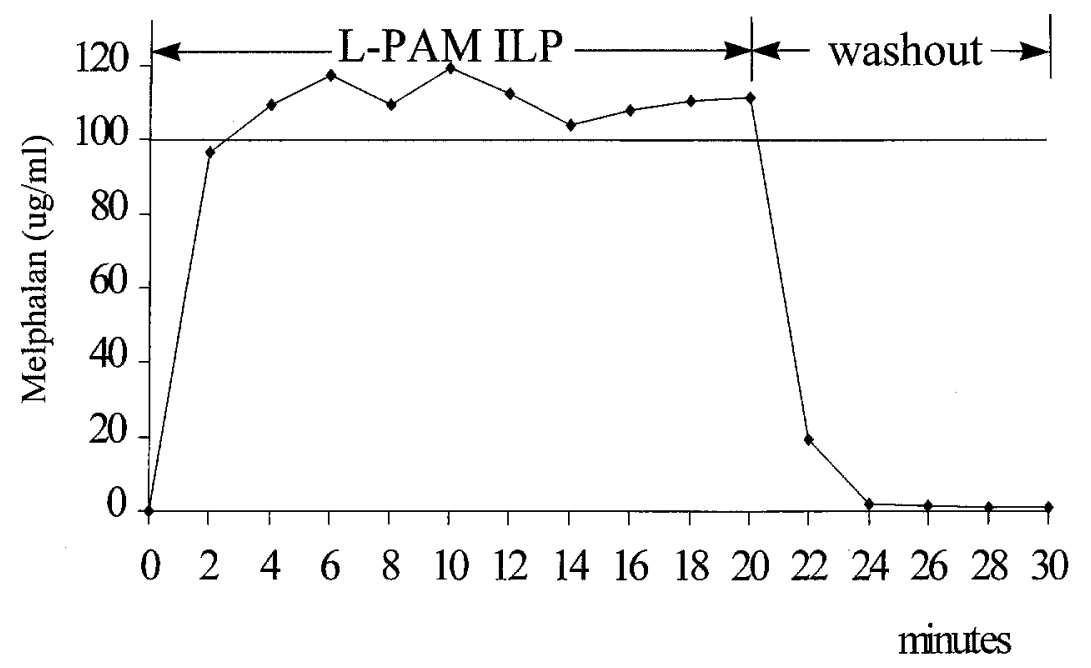

Fig. 2. Melphalan ( $L-P A M)$ levels of venous effluent after ILP with $2 \mathrm{mg}$ of melphalan for 20 minutes and washout with $\mathrm{BHE}$ for 10 minutes.

Table IV. The number of lung sarcoma nodules

\begin{tabular}{|c|c|c|}
\hline & Left lung & Right lung \\
\hline $\begin{array}{l}\text { Melphalan } 1 \mathrm{mg} \text { i.v. } \\
(n=8)\end{array}$ & $60 \pm 21$ & $66 \pm 23$ \\
\hline $\begin{array}{l}\text { Melphalan } 2 \mathrm{mg} \text { ILP } \\
\quad(n=12)\end{array}$ & $7 \pm 10^{*} \dagger$ & $185 \pm 70$ \\
\hline $\begin{array}{l}\text { BHE ILP } \\
\quad(n=11)\end{array}$ & $84 \pm 52$ & $201 \pm 51$ \\
\hline
\end{tabular}

have revealed an antitumor response against soft tissue sarcoma of the extremities with isolated limb perfusion with melphalan alone and more recently with tumor necrosis factor and melphalan..$^{9-13,20-22}$ The effectiveness of melphalan against soft tissue sarcoma via ILP encouraged us to explore melphalan ILP for the treatment of pulmonary sarcoma "metastases."

Toxicity studies determined the maximum tolerated dose of melphalan in our rat ILP model to be $2 \mathrm{mg}$ per rat, with $67 \%$ of the animals surviving subsequent contralateral pneumonectomy. All rats that received $2 \mathrm{mg}$ of melphalan intravenously died within 5 days of injection. The $2 \mathrm{mg}$ dose is equivalent to $8 \mathrm{mg} / \mathrm{kg}$ for a $250 \mathrm{gm}$ rat. The previously reported $10 \%$ lethal dose for rats after intravenous injection of melphalan is $7 \mathrm{mg} / \mathrm{kg}^{23}$

Lung levels of melphalan in the melphalan ILP group were 20 times as high as in the intravenous group. The elevated concentration of lung melphalan in the perfused left lung as compared with the right lung is consistent with results seen in our doxorubicin study ${ }^{7}$ and confirms the ability to deliver higher levels of chemotherapeutic agents to the perfused, tumorbearing organ than does intravenous administration. In the present study, pulmonary venous effluent levels of melphalan approached zero after 2 minutes of BHE washout. Therefore, a significant systemic leak after a 5-minute washout is not possible.

An antitumor effect was evident in the left lungs of animals treated with melphalan ILP. Two rats showed a complete response. Combined synergistic modalities may enhance the tumoricidal effect of melphalan. Some investigators have used hyperthermic isolated limb perfusion with melphalan against soft tissue sarcoma as a preoperative adjunct or as palliative therapy for unresectable tumor and report a local recurrence rate of $11 \%$ to $33 \%$ and a 5 -year survival of $65 \%$ to $80 \% .{ }^{9-12}$ Hill and associates ${ }^{22}$ showed a $100 \%$ complete response rate in patient with soft tissue sarcomas of extremities by isolated limb perfusion with tumor necrosis factor and melphalan. ${ }^{22}$ Rickaby ${ }^{24}$ Cowen, ${ }^{25}$ and their colleagues have shown that hyperthermic lung perfusion is well tolerated by normal lung. Our laboratory has previously revealed that isolated lung perfusion with tumor necrosis factor can be done safely in the rat and is effective in decreasing the growth of sarcomatous lung metastases. ${ }^{26}$

In conclusion, ILP with melphalan is safe and effective in the treatment of sarcomatous pulmonary 
metastases in the rat. Trials evaluating melphalan ILP in patients with isolated pulmonary metastases are warranted.

\section{REFERENCES}

1. Gadd MA, Casper ES, Woodruff JM, McCormack PM, Brennan MF. Development and treatment of pulmonary metastases in adult patients with extremity soft tissue sarcoma. Ann Surg 1993;218:705-12.

2. Lanza LA, Putnam JB Jr, Benjamin RS, Roth JA. Response to chemotherapy does not predict survival after resection of sarcomatous pulmonary metastases. Ann Thorac Surg 1991; 51:219-24.

3. Jablons D, Steinberg SM, Roth J, Pittaluga S, Rosenberg SA, Pass HI. Metastasectomy for soft tissue sarcoma. J Thorac Cardiovasc Surg 1989;97:695-705.

4. Casson AG, Putnam JB, Natarajan G, et al. Five-year survival after pulmonary metastasectomy for adult soft tissue sarcoma. Cancer 1992;69:662-8.

5. Huth JF, Holmes EC, Vernon SE, Callery CD, Ramming KP, Morton DL. Pulmonary resection for metastatic sarcoma. Am J Surg 1980;140:9-16.

6. Weksler B, Schneider A, Ng B, Burt ME. Isolated single lung perfusion in the rat: an experimental model. J Appl Physiol 1993;74:2736-9.

7. Weksler B, Ng B, Lenert JT, Burt ME. Isolated single-lung perfusion with doxorubicin is pharmacokinetically superior to intravenous injection. Ann Thorac Surg 1993;56:209-14.

8. Weksler B, Lenert J, Ng B, Burt M. Isolated single lung perfusion with doxorubicin is effective in eradicating soft tissue sarcoma lung metastases in a rat model. J Thorac Cardiovase Surg 1994;107:50-4.

9. McBride CM, McMurtrey MJ, Copeland EM, Hickey RC. Regional chemotherapy by isolation-perfusion. Int Adv Surg Oncol 1978;1:1-9.

10. Lehti PM, Moseley HS, Janoff K, Stevens K, Fletcher WS. Improved survival for soft tissue sarcoma of the extremities by regional hyperthermic perfusion, local excision and radiation therapy. Surg Gynecol Obstet 1986;162:149-52.

11. Hoekstra HJ, Koops HS, Molenaar WM, Oldhoff J. Results of isolated regional perfusion in the treatment of malignant soft tissue tumors of the extremities. Cancer 1987;60:1703-7.

12. Kettelhack C, Kraus T, Hupp T, Manner M, Schlag P. Hyperthermic limb perfusion for malignant melanoma and soft tissue sarcoma. Eur J Surg Oncol 1990;16:370-5.

13. Lise M, Rossi CR, Alessio S, Foletto M. Multimodality treatment of extra-visceral soft tissue sarcomas M0: state of the art and trends. Eur J Surg Oncol 1995;21:125-35.

14. Burt ME, Lowry SF, Gorschboth CM, Brennan MF. Metabolic alteration in a noncachectic animal tumor system. Cancer 1981;47:2138-46.

15. Popp MB, Morrison SD, Brennan MF. Total parenteral nutrition in a methylcholanthrene-induced rat sarcoma model. Cancer Treat Rep 1981;65:137-43.

16. Weksler B, Ng B, Lenert J, Burt M. A simplified method for endotracheal intubation in the rat. J Appl Physiol 1994;76: 1823-5.

17. Chang SY, Alberts DS, Melnick LR, Waison PD, Salmon SE. High-pressure liquid chromatographic analysis of melphalan in plasma. J Pharm Sci 1978;67:679-82.

18. Scott RN, Black ER, Kerr DJ, et al. Melphalan in isolated limb perfusion for malignant melanoma, bolus or divided dose, tissue levels, the $\mathrm{pH}$ effect. In: Jakesz $\mathrm{R}$, Rainer $\mathrm{H}$, editors. Progress in regional cancer therapy. 1st ed. Berlin: Springer-Verlag, 1990:195-200.

19. Wexler H. Accurate identification of experimental pulmonary metastasis. J Natl Cancer Inst 1966;36:641-5.

20. Lienard D, Lejeune F, Ewalenko P. High dose of r-TNFalpha, r-INF-gamma and melphalan administered in isolation perfusion produced $88 \%$ of complete remissions in melanoma and sarcoma. Reg Cancer Treat 1991;4:27-31.

21. Lienard D, Ewalenko P, Delmontte J, Delmotte JJ, Renard N, Lejeune FJ. High-dose recombinant tumor necrosis factor alpha in combination with interferon gamma and melphalan in isolation perfusion of the limbs for melanoma and sarcoma. J Clin Oncol 1992;10:52-60.

22. Hill S, Fawcett WJ, Sheldont J, Soni N, Williams T, Thomas JM. Low-dose tumor necrosis factor $\alpha$ and melphalan in hyperthermic isolated limb perfusion. Br J Surg 1993;80:995-7.

23. Freireich EJ, Gehan EA, Rall DP, et al. Quantitative comparison of toxicity of anticancer agents in mouse, rat, hamster, dog, monkey and man. Cancer Chemother Rep 1966; 50:219-44.

24. Rickaby DA, Fehring JF, Johnston MR, Dawson CA. Tolerance of the isolated perfused lung to hyperthermia. J Thorac Cardiovasc Surg 1991;101:732-9.

25. Cowen ME, Howard RB, Mulvin D, Dawson CA, Johnston MR. Lung tolerance to hyperthermia by in vivo perfusion. Eur J Cardiothorac Surg 1992;6:167-73.

26. Weksler B, Blumberg D, Lenert JT, Ng B, Fong Y, Burt ME. Isolated single-lung perfusion with TNF- $\alpha$ in a rat sarcoma lung metastases model. Ann Thorac Surg 1994;58:328-31.

\section{Discussion}

Dr. Frank Baciewicz (Detroit, Mich.). We have treated patients clinically with doxorubicin and have not been impressed with the results. In your study I noticed that a number of animals receiving BHE died just before contralateral pneumonectomy. The first question is this: What does BHE do to the lung? Also, in your efficacy study it appeared that BHE caused a significant decrease in the number of nodules in the treated lung. It seemed that there was a good effect with just BHE. What effect does BHE have on the number of nodules in this model?

Dr. Nawata. In our first experiment, all rats perfused with $20 \mathrm{mg}$ of melphalan died immediately after perfusion, but rats perfused with $\mathrm{BHE}$ all survived perfusion, and $20 \%$ of these rats died after contralateral pneumonectomy. I think this mortality is not from a toxicity of $\mathrm{BHE}$, but from a technical error. In our efficacy study, rats underwent 20 -minute anoxic perfusion. I think this is why the BHE group demonstrated a reduction in the number of tumor nodules.

Dr. Joe B. Putnam, Jr. (Houston, Tex.). Dr. Nawata, I applaud the efforts that have gone into this work and, as well, the contributions that you and the surgeons at Memorial have made toward the treatment of pulmonary metastasis. The information you presented indicates value in isolated pulmonary perfusion for the treatment of pulmonary metastases in your animal model. However, the translation of this work from the animal model to the human being still is undergoing effort and revision.

In your rat model the sarcoma cell line is homogeneous, 
whereas in the human model sarcomas are heterogeneous. Have you evaluated this drug in the treatment of other rat sarcoma cell lines? Second, how did the dose selected in your rat model compare with the dose that has been previously used in human beings for the isolated limb perfusion?

Dr. Nawata. To answer the first question, we have not evaluated another sarcoma cell line in the rat. To answer the second question, in human isolated limb perfusion, previous reports showed that the melphalan concentration of tissue or tumor was dependent on melphalan concentration of perfusate. They used 60 to $80 \mathrm{mg}$ of melphalan $(0.6$ to $1.0 \mathrm{mg} / \mathrm{kg}$ in the upper limb, 0.8 to $1.2 \mathrm{mg} / \mathrm{kg}$ in the lower limb). In our efficacy study, we used $2 \mathrm{mg}$ of melphalan per rat $(8 \mathrm{mg} / \mathrm{kg})$.

Dr. Keith S. Naunheim (St. Louis, Mo.). Dr. Nawata, can you tell us a little bit about the histology of the lung away from the sarcoma, what sort of inflammatory and damaging effects there are histologically from the melphalan?

Dr. Nawata. Rats perfused with $20 \mathrm{mg}$ of melphalan died immediately after ILP. Rats perfused with $5 \mathrm{mg}$ of melphalan tolerated ILP but died after contralateral pneumonectomy. The lungs of those rats that were per- fused with $20 \mathrm{mg}$ or $5 \mathrm{mg}$ of melphalan showed severe hemorrhage and congestion. The lungs of the rats perfused with $2 \mathrm{mg}$ of melphalan had alveolar cell hyperplasia and pneumonitis characterized by mild-to-moderate inflammatory cell infiltration consisting primarily of mononuclear cells with occasional neutrophils that was similar to findings in the control group.

Dr. Larry R. Kaiser (Philadelphia, Pa.). You inject the MCA sarcoma on day 0 , and you wait until day 7 before you do your perfusion. Are there visible nodules at that time or are there just microscopic nodules? Have you looked at them at day 7? Also, have you looked at the immune component? That is, after treating these tumorbearing animals, have you looked at the inflammatory cells that may be collecting in the lung as well? As was pointed out by one of the discussants, even in your control group you had a reduction in the number of nodules.

Dr. Nawata. We have not evaluated the role of the immune system in our model.

Dr. Kaiser. Do you have visible nodules on day 7 in your model?

Dr. Nawata. By day 7 we have microscopic disease. We can see macroscopic nodules by day 10 to 12 . 